\title{
Offshore Wind Farms with Low Frequency AC Transmission Connection to the Main Grid
}

\author{
Padala Lakshmi ${ }^{1}$, Shaik Hussain Vali ${ }^{2}$, Asapu Siva ${ }^{3}$ \\ PG Student, EEE, JNTUK-UCEV, Vizianagaram, India ${ }^{1,3}$ \\ Assistant Professor, EEE, JNTUK-UCEV, Vizianagaram, India ${ }^{2}$
}

\begin{abstract}
This paper presents an Offshore Wind Farms with Low Frequency AC Transmission Connection to the Main Grid. In present years the electricity produced from wind has grown rapidly. Offshore wind farm is currently seen as a promising solution to satisfy the growing demand for renewable energy source. The main reasons for the rapid development of offshore wind farms includes much better wind resources and smaller environmental impact. The possible solutions for transmitting power from wind farms are HVAC, Line commutated HVDC and Voltage source based HVDC (VSC-HVDC). The limitations of both the HVAC and HVDC technologies when applied for far offshore wind farm connection Low Frequency AC (LFAC) transmission system is a new and alternating solution. In LFAC systems, an intermediate-frequency level is used, which is created using a cycloconverter that lowers the grid frequency to a smaller value, typically to one-third its value. For interconnecting the offshore wind farms with Low Frequency AC (LFAC) transmission system for improving the transmission capability and distance compared to the conventional $\mathrm{AC}$ solution at the nominal frequency, e.g. $50 \mathrm{~Hz}$ or $60 \mathrm{~Hz}$. The dc collecting system with series connected wind turbines are used at the offshore to reduce the cabling requirement. The wind power plant collection system is dc based, and connects to the LFAC transmission line with a 48-pulse converter. The output waveforms are observed in MATLAB.
\end{abstract}

Keywords: Power transmission, wind energy, thyristor converters, low frequency AC (LFAC), cycloconverter.

\section{INTRODUCTION}

In recent years, renewable energy sources have experienced dramatic innovations and improvements in terms of both quality and quantity with increased pressure to overcome environmental problems and economical crisis from increased prices of non-renewable natural resources. Especially, grid-connected wind farms have been developed very quickly and the penetration of wind energy in the grid is rapidly increasing. Since wind power is randomly varying and it has to be captured over a wide area for stable and reliable operations, offshore wind farms have been very attractive to overcome the space shortage on shore and to capture high quality wind.

To transmit electrical energy from offshore wind farms into the main $60 \mathrm{~Hz}$ AC grid or central loads, several transmission systems have been proposed: High Voltage Alternating Current (HVAC) and High Voltage Direct Current (HVDC) systems are well established transmission technologies. In case of the HVAC systems, long submarine cables interconnecting wind farms suffer from excessive reactive power requirement due to the capacitance of the cables and associated electrical losses, and need for inductive compensation.

However, it is impractical or economically infeasible for submarine cables, since the breakeven distance is not exceeding $50 \mathrm{~km}$ via $\mathrm{HVAC}$ cable systems in economical aspects. HVDC transmission systems also have been used for offshore wind farms. Since HVDC cable transmission is not affected from the capacitance, the HVDC systems are technically feasible for lengths of hundreds of kilometers to transmit electrical energy. However, HVDC systems are expensive solutions to connect offshore wind farms from short and intermediate distances.
The converter substation has to be installed nearby the wind farms on the sea, and thus the initial investment costs for HVDC systems are more expensive than those of onshore wind farms [1].

Low Frequency Alternating Current (LFAC) transmission systems represent more cost effective technology than the HVDC system for intermediate distances $(50-150 \mathrm{~km})$. The basic concept of the LFAC transmission is to use a frequency $(16.666 / 20 \mathrm{~Hz})$ lower than nominal frequency $(50 / 60 \mathrm{~Hz})$ by introducing a phase-controlled thyristor cycloconverter. This usage makes economics of low frequency transmission systems more effective. For example, rating voltage of electrical switches in converters can be reduced, and high voltage transmission is available, since existing standard transformers can be also used in low frequency transmission [2].

\section{PRINCIPLE OF LFAC TRANSMISSION SYSTEM}

For AC transmission system, the active power $(P)$ transmitting over the transmission lines, which should be cables for connecting offshore wind farms, which can be expressed by

$$
P=\frac{V_{S} V_{R}}{X_{L}}
$$

Where $V S$-sending end voltage and VR-receiving end voltages respectively. $X L$ is line reactance. The above equation is valid when the cable is short that neglects the effect of the line angle and increasing transmitting power is either by increasing the voltage level or lowering the impedance of the cable. Furthermore, with the fixed 
sending end voltages, the only way to improve the transmission capability by reducing the impedance of the cable. The reactance is proportional to power frequency $\mathrm{f}$,

$$
X_{L}=2 \pi f L
$$

Where $\mathrm{L}$ is total inductance over the line, decreasing the electricity frequency can proportionally increase the transmission capability. The LFAC system uses low frequency to reduce the reactance of the transmission system thus, its transmission capacity can be increased several fold. When frequency is $50 / 3 \mathrm{~Hz}$, the theoretically transmission capability can be raised three times. The LFAC system can also improve the voltage stability given the same amount of reactive power transmission as given in eq.

$$
\% \Delta V=\frac{Q X}{V^{2}} \times 100
$$

Where $\Delta \mathrm{V}$ is the voltage drop over the cable, $\mathrm{V}$ is the nominal voltage and $\mathrm{Q}$ is the reactive power flow of the cable. The impedance is reduced in the LFAC system due to the power lower grid frequency, the voltage drop over the cable is proportionally reduced accordingly [3].

\section{PROPOSED LOW FREQUENCY AC TRANSMISSION SYSTEM CONFIGURATION}

The proposed configuration of LFAC system could be built with commercially available power system components. Fig. 1 represents interconnection of the wind power plant to the main power grid through LFAC transmission system. The main reason for using DC collection system with LFAC transmission system is that wind turbine would not need to be redesigned to output low frequency AC power which would leads to heavier and costlier components. At the sending end of the proposed LFAC system, a DC/AC 48-pulse inverter is used to generate low frequency $(20 \mathrm{~Hz}$ or $162 / 3 \mathrm{~Hz})$ ac power. The phase shift transformer used at the sending end could be a $60 \mathrm{~Hz}$ transformer decreased by a factor of three, with same rated current but only one third of original rated voltage. At the receiving end, a thyristor based cycloconverter is used as an interface between the low frequency side and $60 \mathrm{~Hz}$ or $50 \mathrm{~Hz}$ power grid. LFAC transmission could be an attractive technical solution for medium distance transmission.

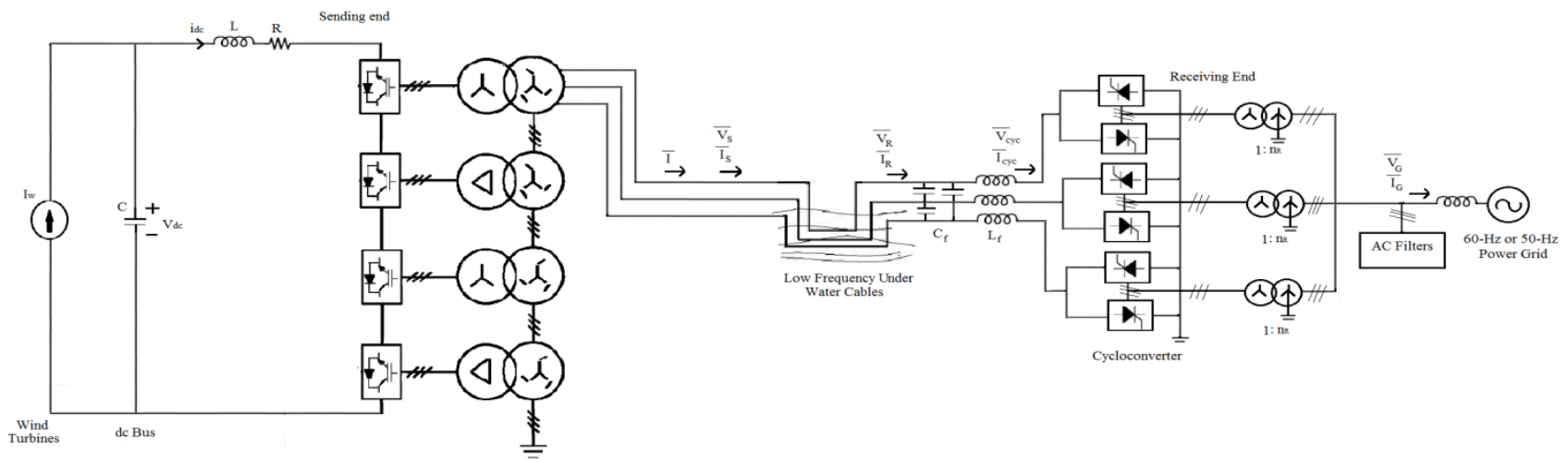

Fig.1 Configuration of Proposed LFAC transmission system

\section{OPERATION OF LFAC SYSTEM}

LFAC transmission system can be understood to proceed as follows. First, the cycloconverter at the receiving end is activated, and the submarine power cables are energized by a $20-\mathrm{Hz}$ voltage. In the meantime, the dc collection bus at the sending end is charged using power from the wind turbines. After the $20-\mathrm{Hz}$ voltage and the dc bus voltage are established, the 48-pulse inverter at the sending end can synchronize with the $20-\mathrm{Hz}$ voltage, and starts the transmission of power. In reality, more sophisticated schemes for system startup would have to be devised, based nevertheless on this operating principle.

The following assumptions are considered for the steady state analysis of LFAC transmission systems.

- Only fundamental components of voltages and currents are considered. The receiving end is modeled as a $20-\mathrm{Hz}$ voltage source of nominal magnitude.

- The power losses of the reactor, thyristors, filters, and transformers are ignored.

- The resistances and leakage inductances of transformers are neglected.
- The ac filters are represented by an equivalent capacitance corresponding to the fundamental frequency.

- The design is based on rated operating conditions (i.e., maximum power output).

\section{DESIGN OF WIND TURBINE}

Permanent-magnet synchronous generators (PMSGs) are considered in this paper for their attractive power density and efficiency, which makes them good for offshore application. PMSGs are particularly suited for dc connection due to their need for fully rated power converters for variable speed operation [6].

Offshore wind plants are expected to represent a significant component of future electric generation due to greater space availability and better wind potential [6]-[8]. Electric power can be produced from wind energy by using wind turbine generator. The maximum power extracted from the wind is given as

$$
P_{m}=\frac{1}{2} \rho A C_{p}(\lambda, \beta) \mathrm{V}_{\text {wind }}^{3}
$$




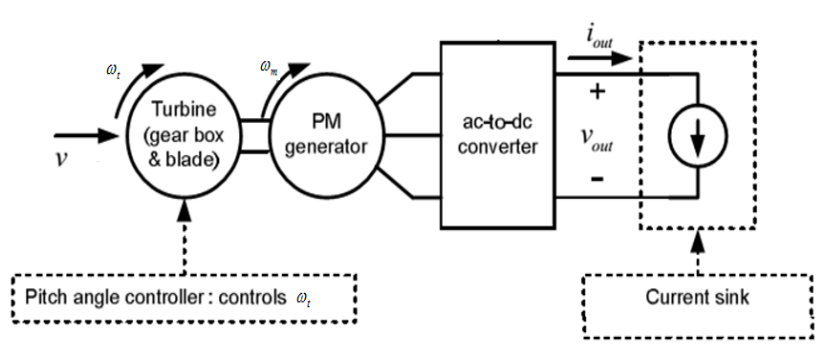

Fig.2 PMSG wind configuration

Where $(\rho)$ is the air density in $[\mathrm{kg} / \mathrm{m} 3]$ and (A) is the area in $\left[\mathrm{m}^{2}\right]$ covered by the wind turbine rotor of radius (R) defined in $[\mathrm{m}]$. The power coefficient $\left(C_{p}\right)$ is a nondimensional term specific for each wind turbine. The output of PMSG is converted to dc power through a thyristor converter. The output power of the wind turbine $P t$, which is equal to converted dc power if the losses in the generator and converter are neglected, is given by

$$
P_{t}=\frac{1}{2} C_{p}(\lambda, \beta) \rho \mathrm{A} V^{3}{ }_{\text {wind }}=V_{d} I_{d}
$$

Where $V d$ and $I d$ are the output voltage, and current of the converter, respectively.

\section{INVERTER CONTROL}

The control structure for the sending-end inverter is shown in Figure. The controller regulates the dc bus voltage by adjusting the voltage at the inverter terminals. The cosine wave crossing method is applied to determine the firing angle. Where linearity of transfer characteristics is achieved is known as cosine wave crossing method. 48 pulse inverter control configuration is shown in fig.4.2. The inputs of the PLL model are the three phase voltages measured on the 20-HZ side and the output is the tracked phase angle. The PLL model is implemented in synchronous $\mathrm{dq}$ reference frame, where a Park transformation is used. The sine wave supply voltage is phase advanced by $\pi / 2$ to generate a cosine wave; it is phase inverted every second half cycle to construct the cosine wave shown in Fig.3.[12]

The firing angle $\alpha$ is generated by the crossover point of control voltage $V_{c}$ and cosine wave at every half cycle as

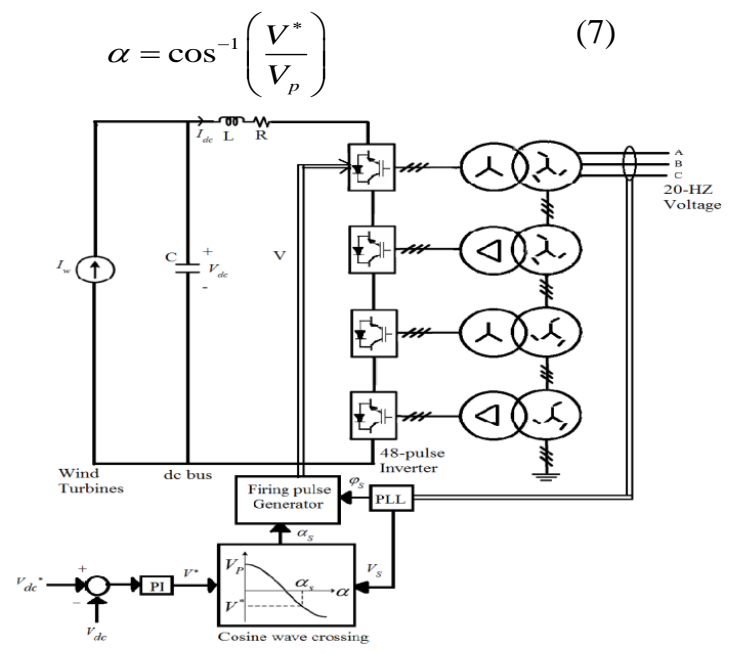

Fig.3 Inverter control

\section{CYCLOCONVERTER CONTROL}

The structure of receiving end controller is illustrated in Fig.4. The objective of controller is to provide a constant $20 \mathrm{~Hz}$ voltage and to modulate frequency, magnitude and phase angle of output voltage. The frequency level is limited to $20 \mathrm{~Hz}$ because higher frequency can cause distortion. The basic principle of controller is to continuously vary the firing angles of converters. Cosine wave crossing method with circulating current free mode operation is considered for switching sequence. According to the controller algorithm, partial circulating current mode can prevent discontinuous operation during bank exchange function from positive to negative bank with minimal circulating loss. Cosine wave crossing method is used to reduce total harmonic distortion (THD) of output voltages [12].

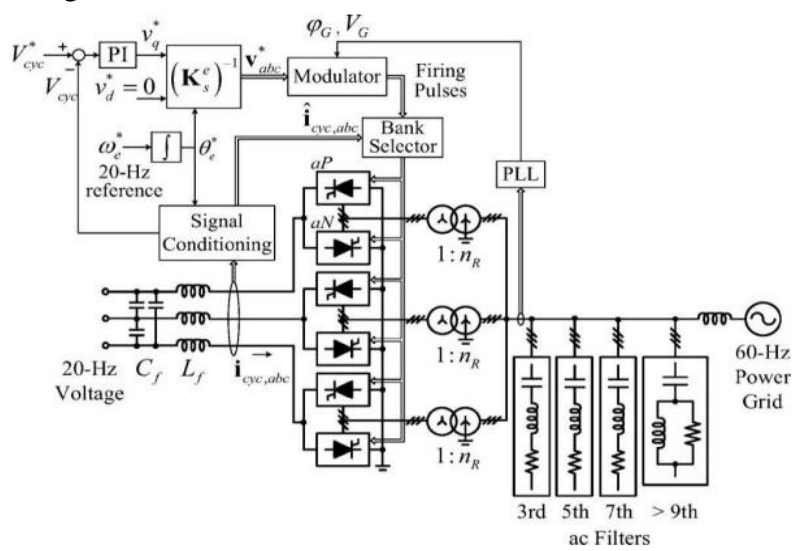

Fig.4 Cycloconverter control

The fundamental component of cycloconverter voltage is obtained with the signal conditioning block shown in Fig.5

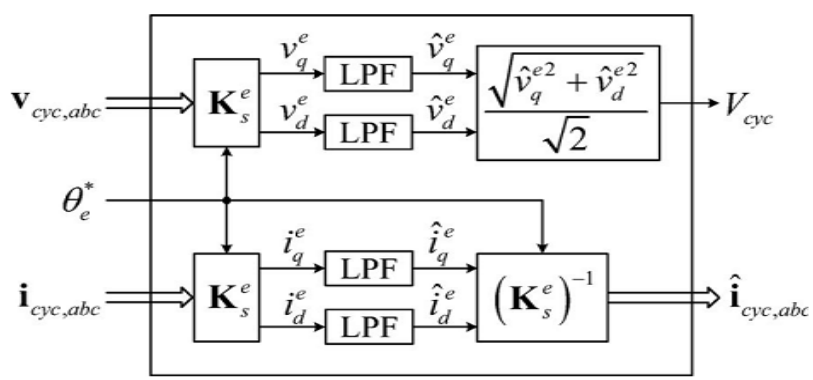

Fig.5 Signal conditioning block

For the positive converter, the positive converter the average voltage at $20 \mathrm{~Hz}$ terminal is given by

$$
V_{a P}=\frac{3 \sqrt{6} V_{G}}{\pi n_{R}} \cos \left(\alpha_{a P}\right)
$$

Where $V_{G}$ is the rms value of the line-to-neutral voltage at the grid side, and $n_{R}$ is the turns ratio of the transformers. The condition $\alpha_{p}+\alpha_{N}=\pi$ ensures that average voltages with the same polarity are generated from the positive and negative converter at the $20-\mathrm{Hz}$ terminals. The firing pulses $S_{a P}$ and $S_{a N}$ are not simultaneously applied to both converters, in order to obtain a non circulating current mode of operation. This functionality is embedded in the "Bank Selector" block is shown in Fig.5. Which operates based on the filtered current $\hat{i}$ [13] 


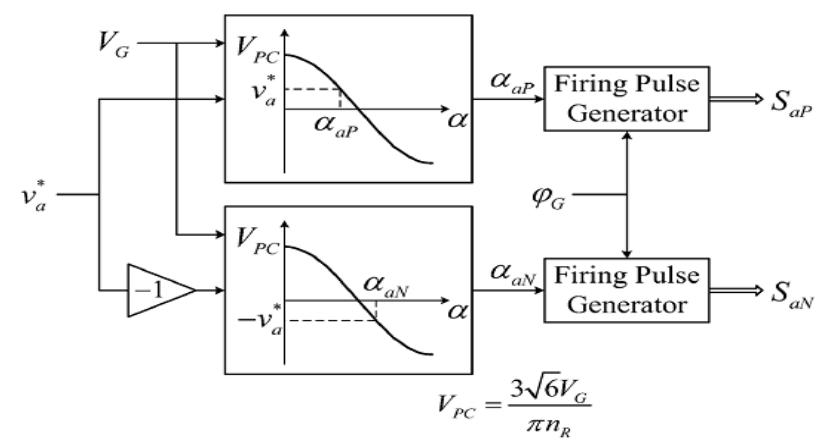

Fig.6 Modulator for phase a

The $\alpha$ modulator receives the biased cosine signal waveform and sinusoidal control signal voltage to generate the firing angles of the converter. Modulator for phase a as shown in Fig.6.

\section{SIMULATION RESULTS}

The 20-Hz LFAC system is designed to transmit $180 \mathrm{MW}$ over $160 \mathrm{~km}$. At the sending end, the dc bus voltage level is chosen as $30 \mathrm{kV}$. The rating of wind power plant is $180 \mathrm{MW}$ which is transmitted over a distance of $160 \mathrm{Km}$. The transmission voltage is chosen as $132 \mathrm{kV}$. The power grid voltage is $132 \mathrm{kV}$ line to line.

Simulation results are shown for the $20 \mathrm{~Hz}$ LFAC transmission system. To demonstrate the validity of the proposed LFAC system, simulations have been carried out by using Matlab/Simulink software.

The steady state line to line voltage and current waveforms at the sending end, the receiving end, the $20 \mathrm{~Hz}$ side of the cycloconverter and $60 \mathrm{~Hz}$ power grid side simulation results are as shown below.

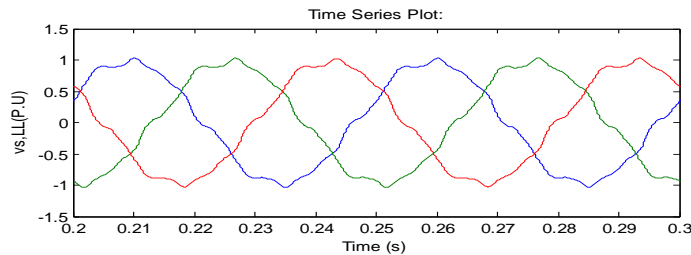

Fig.7 simulated voltage at sending end side

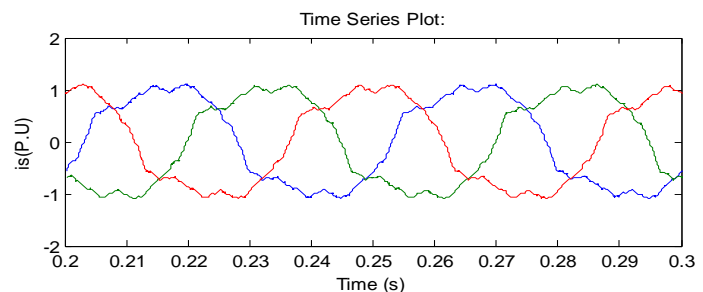

Fig.8 simulated current at sending end side

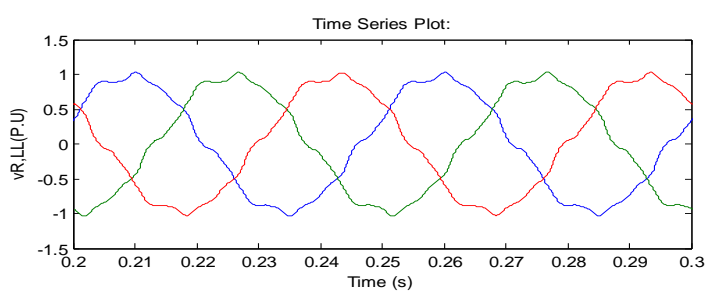

Fig.9 simulated voltage at receiving end side

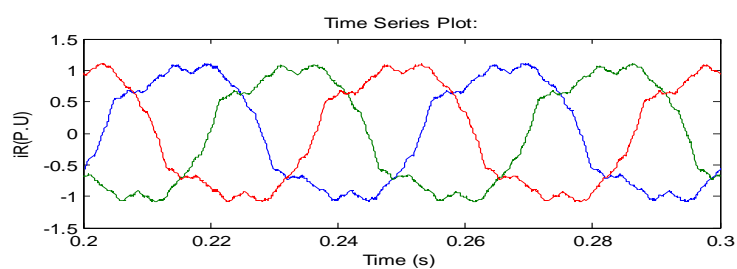

Fig.10 simulated current at receiving end side

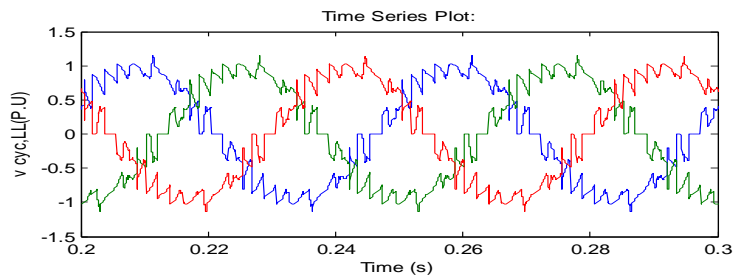

Fig. 11 simulated voltage at cycloconverter $20 \mathrm{~Hz}$ side

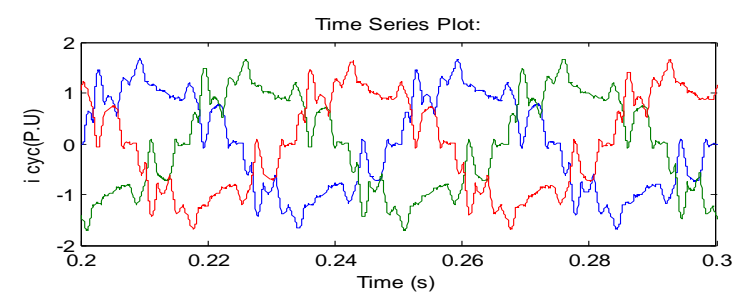

Fig. 12 simulated current at cycloconverter $20 \mathrm{~Hz}$ side

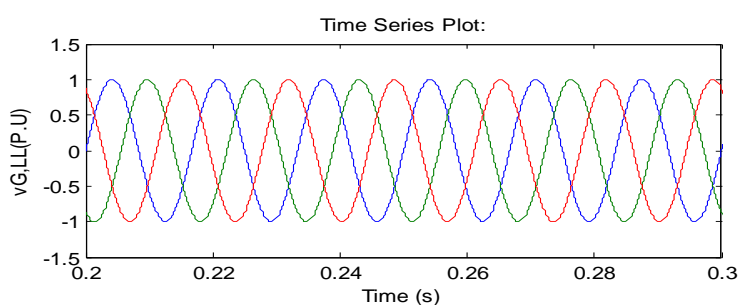

Fig. 14 simulated voltage at $60 \mathrm{~Hz}$ grid side

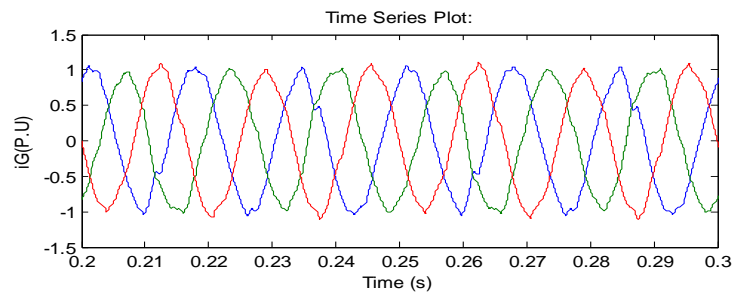

Fig. 15 simulated current at $60 \mathrm{~Hz}$ grid side

\section{PROPOSED LFAC SYSTEM SIMULATION PARAMETERS}

- Transmission line nominal voltage: $132 \mathrm{Kv}$

- Transmission line maximum voltage: $145 \mathrm{kV}$

- Transmission line rated current: $825 \mathrm{~A}$

- Cable parameters: resistance $17.6 \mathrm{~m} / \mathrm{km}$, inductance $0.35 \mathrm{mH} / \mathrm{km}$, and capacitance: $0.25 \mu \mathrm{F} / \mathrm{km}$

- Total wind power: $180 \mathrm{MW}$

- Transmission line distance: $160 \mathrm{~km}$.

- DC bus capacitance: $1000 \mu \mathrm{F}$

- Sending end transformer ratings: 50MVA, 132/13.2kV, $20 \mathrm{~Hz}$

- Receiving end transformer rating: 100MVA, 132/88kV

- AC filters at receiving end : 200MVAr 


\section{CONCLUSION}

A low-frequency ac transmission system for offshore wind power has been proposed. A method to design the system's components and control strategies has been discussed. The use of a low frequency can improve the transmission capability of submarine power cables due to lower cable charging current. The proposed LFAC system appears to be a feasible solution for the integration of offshore wind power plants over long distances, and it might be a suitable alternative over HVDC systems in certain cases. Furthermore, it might be easier to establish an interconnected low-frequency ac network to transmit bulk power from multiple plants.

\section{REFERENCES}

[1] N. B. Negra, J. Todorovic and T. Ackermann, "Loss Evaluation of HVAC and HVDC transmission solutions for large offshore wind farms," Elect. Power Syst. Res, vol. 76, no. 11,(2006) July, pp. 916927.

[2] T. Funaki and K. Matsuura, "Feasibility of the lower frequency AC transmission", in proc. IEEE Trans.Power Eng. Soc.Winter Meeting, vol. 4, (2000), pp. 2693-2698.

[3] N. Qin, S. You, Z. Xu and V. A. Khmatov, "Offshore wind farm connection with low frequency AC transmission technology," presented at the IEEE Power Energy Soc. Gen. Meeting, Calgary, AB,Canada, (2009).

[4] X. Wang, C. Cao and Z. Zhou, "Experiment with fractional frequency transmission system, IEEE Trans.Power Syst., vol.21, no. 1 , (2006) February, pp. 372-377.

[5] Y. Cho, G. J. Cokkinides and A. P. Meliopoulous, "Time domain simulation of a three phase cycloconverter for LFAC transmission system", presented at the IEEE Power Energy Soc. Transm. Distib. Conf. Expo, Orlando, FL, (2012) May.

[6] M. Lierre, R. Cardenas, M. Molinas and J. Rodriguez, "Overview of multi-MW wind turbines and wind parks, IEEE Trans. Ind. Appl., vol. 43, no. 6, (2007) November/December, pp. 1475-1482.

[7] C. Meyer, M. Hoing, A. Peterson and R. W. De Doncker, "Control and design of DC grids for offshore wind farms", IEEE Trans. Power Del., vol. 25, no. 4, (2010) October, pp. 2308-2318.

[8] J. Yang, J. Fletcher and J. O Reilly, "Multi-terminal DC wind farm collection grid internal fault analysis and protection design", IEEE Trans. Power Del., vol. 25, no. 4, (2010) October, pp. 2308-2318.

[9] J. Robimson, D. Jovcic and G. Joos, "Analysis and design of an offshore wind farm using a MV DC grid", IEEE Trans.Power Del., vol. 25, no. 4, (2010) October, pp. 2164-2173.

[10] A. Prasai, J-S. Yim, D. Divan, A. Bendre and S. K. Sul, "Anew architecture for offshore wind farms," IEEE Trans. Power Electron., vol. 23, no. 3, (2008) May, pp.1198-1204.

[11] M. H. Johnson, H. Chen and D. C. Aliprantis, "Offshore wind farm with de collection system," IEEE Power Energy Conf., Urbana, IL, (2013) February.

[12] B. K. Bose, "Modern Power Electronics and AC Drives", Upper Saddle River, NJ: Prentice-Hall, (2002).

[13] B. R. Pelly, "Thyristor Phase Controlled Converters and Cycloconverter", New York: Wiley, (1971).

[14] B. Wu, "High-Power Converters and AC Drives", Hoboken, NJ Wiley, (2006). 